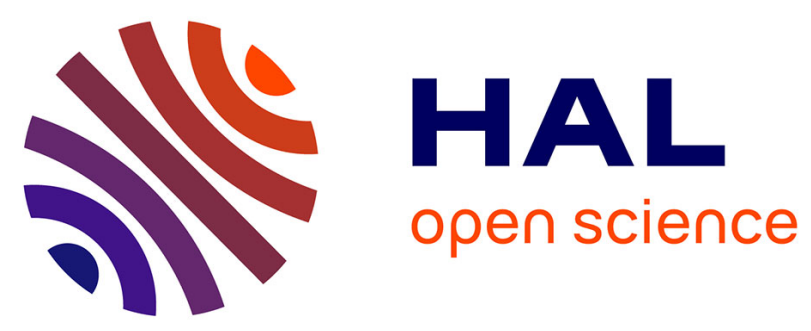

\title{
Carbon capture and sequestration: how much does this uncertain option affect near-term policy choices?
}

Laurent Gilotte, Valentina Bosetti

\section{To cite this version:}

Laurent Gilotte, Valentina Bosetti. Carbon capture and sequestration: how much does this uncertain option affect near-term policy choices?. 2006. halshs-00007298

\section{HAL Id: halshs-00007298 \\ https://shs.hal.science/halshs-00007298}

Preprint submitted on 16 Jun 2006

HAL is a multi-disciplinary open access archive for the deposit and dissemination of scientific research documents, whether they are published or not. The documents may come from teaching and research institutions in France or abroad, or from public or private research centers.
L'archive ouverte pluridisciplinaire HAL, est destinée au dépôt et à la diffusion de documents scientifiques de niveau recherche, publiés ou non, émanant des établissements d'enseignement et de recherche français ou étrangers, des laboratoires publics ou privés. 


\title{
Carbon Capture and Sequestration: how much does this uncertain option affect near-term policy choices?*
}

\author{
Laurent Gilotte ${ }^{1, \star}$ Valentina Bosetti ${ }^{2}$ \\ ${ }^{1}$ CIRED, Jardin Tropical, 94736 Nogent-sur-Marne Cedex, France \\ ${ }^{2}$ Fondazione Eni Enrico Mattei, Corso Magenta 63, 20123 Milano, Italy
}

November 10, 2005

${ }^{\star}$ Corresponding author:

CIRED

Jardin Tropical

45 bis, avenue de la Belle Gabrielle

94736 Nogent-sur-Marne Cedex

France

Tel.:+33-1-43947385; fax:+33-1-43947370

Email address: gilotte @ centre - cired .fr

${ }^{*}$ We thank Mihn Ha-Duong and Khalil Helioui for their comments and suggestions. Laurent Gilotte has benefited from a Marie Curie fellowship of the European Commission under contract HPMT-CT2001-00373.. All remaining errors are from the authors. 


\begin{abstract}
Policy makers as well as many economists recognize geological Carbon Capture and Sequestration (CCS) as a key option to avoid costly emission reduction. While an extreme perspective is to envision CCS as a magic bullet to solve the issue of climate change, the economics perspective is more balanced and see it as a part of a portfolio of mitigation actions. Besides, as any novel mitigation technology, CCS can be implemented with a twofold purpose; on one side it can substitute some other technological efforts to reach a given environmental target. On the other side, it offers the opportunity to go for additional emission reductions and reach a "safer" climate target. In order to balance these two possible utilizations of CCS and assess their respective effects on early policystrategies, we undertake a twofold numerical experiment. First, a cost-efficiency analysis is undertaken where CCS sole effect is substitution of other efforts. This is followed by a cost-benefit analysis where both purposes have to be balanced. We find that future availability of CCS is less a reason to relax near-term abatement efforts than what could be inferred from previous analyses. Moreover, cost-benefit analysis indicates that the environmental target should be more ambitious when CCS is included in the picture.
\end{abstract}

KEYWORDS: Climate Change, Uncertainty, Sequestration, Cost-benefit analysis 


\section{Introduction}

Carbon Capture and Sequestration (CCS) technologies are receiving increasing attention, mainly for their potential contribution to the optimal mitigation of carbon dioxide emissions that is intended to avoid future, dangerous climate change. CCS technologies attract a lot of attention because they could allow "to reduce our CO2 emissions to the atmosphere whilst continuing to use fossil fuels" [10].

The main policy question we address here is whether CCS technologies should be seen as a way to bypass immediate costly abatement action, while waiting for better information on the climate change issue. Deferring emission reductions is politically attractive for it avoids requiring explicit efforts from the populations. Thus, to policy makers who tend to oppose the notion of early abatement, CCS technologies offer a credible argument for postponing efforts. Conversely, in this paper it is argued that, given a cost-benefit analysis framework, CCS technologies represent a mean to reach emission trajectories lower than that proposed otherwise. Therefore, they offer an opportunity that should be envisioned in a perspective broader than that of a costefficiency analysis. If globally, large scale implementation of carbon sequestration could have a significant impact on our future emissions, should not we take it as a chance to adopt a climate target tighter (and safer) than the doubling of pre-industrial atmospheric carbon dioxide (550 ppmv)? This article uses a set of numerical simulations and assesses the relevance of the future availability of CCS for designing near-term (first decades) abatement policy and for the choice of an optimal climate target. Moreover, the uncertainty surrounding the climate cycle is considered. This allows to investigate 
how largely future availability of CCS technologies impacts the optimal hedging policy. Simulation experiments show that three main conclusions can be drawn.

(a) The environmental target that can be derived by applying a Cost-Benefit analysis should be more ambitious (stringent) if CCS is considered as an option that might become available.

(b) Cost-benefit analysis indicates that the future availability of CCS is much less a reason to bypass near-term abatement efforts than what is suggested by cost-efficiency analysis.

(c) Under standard assumptions about damages and climate sensitivity uncertainty, the substitution of near-term abatement by sequestration almost vanishes. Until information is obtained, emission reductions deriving from sequestration are purely additional to the abatement efforts.

These results are somewhat more conservative and they imply a more contained impact of CCS technologies on near term climate policy strategies than what can be inferred from studies elsewhere. Some recent analyses have used detailed bottom-up models in a cost-minimization framework [23, 1]. They emphasized that after 2050 carbon dioxide emissions could be significantly and increasingly curbed thanks to sequestration. Results in these publications show that, in 2100, sequestration could account for around $40 \%$ of the reduction required to stabilize carbon atmospheric concentration to 550 ppmv. In particular, Akimoto et al. [1] present a sensitivity analysis and suggest that this $40 \%$ contribution is relatively robust against changes in the CCS costs. But these results also suggest that few abatement efforts should be undertaken before 2030 
to reach the 550 ppmv stabilization target $[23,1]$. This effect is confirmed even under an hypothesis of high emissions baseline [1]. Analyses that have used the cost-benefit framework have been focused on forest-based sequestration [15] or on the issue of the non-permanency of the sequestration $[15,9,13]$. In particular, in Keller et al. [13] the impact on the optimal carbon tax of the availability of sequestration technologies is considered and appears to be insignificant before 2100; this also suggests that abatement policies before that date should remain unchanged. However, this result seems to be prompted by the assumption of a rather high marginal cost for sequestration (100 USD per ton $\mathrm{C}$ ) which delays the adoption of the option much later into the future than recent contributions suggest $[1,23]$.

Many publications have addressed the implications of the prevailing scientific uncertainties on optimal climate policy strategies. In particular, how climate uncertainty affects optimal emissions reduction strategies and how it should be included in the analysis (see for instance Nordhaus [18, chapter 8], and also [21, 14, 20, 12]).

In the present paper, we begin with a description of the model in Section 2. Section 3 describes the different scenarios simulated and presents the main results. Section 4 concludes.

\section{Model and Simulations Description}

The model we used is based on the latest version of Nordhaus' DICE [19], an optimal economic growth model of the global economy that includes a climate module linked to carbon emissions deriving from the economic activity. The version we use departs 
from the original DICE: it is structured in order to allow for sequential revision of decisions in the face of uncertainty and learning about climate risks. To this end, it is formulated as a probabilistic optimization problem, which maximizes the expected utility of consumption. After the date of learning, expected utility is conditional on the knowledge gained. This approach was also used in previous studies as in Nordhaus [18, chapter 8] and in Nordhaus and Popp [20].

In substitution to the original damage function, some of the simulations use a threshold damage function that we describe in details below. With this function, for temperatures under 2.5 and above 5.5 damages are lower than with the usual specification, but increase rapidly when the temperature increase ranges between $2.5-3{ }^{\circ} \mathrm{C}$.

Finally, and this is the main novelty presented in the paper, as an alternative to traditional abatement effort we include in the model the option of carbon capture and geological sequestration (CCS).

For a formal description of the model the reader is referred to the appendix A where model equations are set out. To provide a general sketch of the model, emissions are proportional to gross economic output and the carbonization ratio decreases exogenously over time. The central planner can choose the level of emissions through a variable representing the rate of mitigation. To this abatement option an alternative decision variable is added, accounting for the abatement rate due to CCS technologies. Before heading to the results of the simulated policy scenarios, we present in detail some relevant features of the model. 


\section{Costs of carbon capture and sequestration}

The current estimated costs associated to CCS technologies are rather high. While injection costs are variable and extremely dependent on the reservoir type and on local condition [4], the costs for capture and transport represent the largest part. They are estimated between 35 and 264 USD per ton $\mathrm{C}$ for CO2 capture and transport from power plants [23]; for the cement industry, the range is 183-917 USD/tC [10]. However, costs for capture and transport will possibly decrease through the century, mainly due to learning-by-doing. Besides, the physical potential for storage could be very large: for underground storage ${ }^{1}$ alone, global estimates range between 960 and 1,450 GtCO2 (40-390 GtC), while, the capacity of deep saline aquifers is estimated between 6,000 and 10,000 GtCO2 (1,600-2,750 GtC) [Table TS5, IPCC 2005 Technical Report on CCS].

In the model, we take a rule of thumb assumption concerning costs of CCS technologies, which are assumed to be quadratic in the level of effort with a linear component of $10 \mathrm{USD} / \mathrm{tC}$ and marginal costs increasing up to $400 \mathrm{USD}$, as proposed by R. Gerlagh and B. van der Zwaan ${ }^{2}$. We take $10 \mathrm{GtC}$ per year as the maximum volume of CCS (corresponding to the marginal cost of $400 \mathrm{USD} / \mathrm{tC}$ ). Besides, no leakages or auto-consumption of energy are assumed for CCS.

\footnotetext{
${ }^{1}$ In porous and permeable reservoir stocks, depleted oil and gas fields, and coal beds [10].

${ }^{2}$ R. Gerlagh and B. van der Zwaan, 2004, presentation at the 2nd international workshop on integrated climate models: an interdisciplinary assessment of climate impacts and policies. 29-20 November 2004, Trieste. 'Instrument choice for a deep cut in carbon dioxide emissions'.
} 


\section{Damage function}

The damage function defines the share of GWP lost due to climate change. In the original DICE model, damage, $D(\cdot)$, is a quadratic function of the atmospheric temperature increase, $\theta_{t}, D\left(\theta_{t}\right)=a_{1} \theta_{t}+a_{2}\left(\theta_{t}\right)^{2}$. In this article, we also derive results given a threshold damage function as proposed in [2] and defined by ${ }^{3}$ :

$$
D\left(\theta_{t}\right)=b\left(\theta_{t}-\theta_{0}\right)+\frac{d}{1+\exp \left[\frac{K+Z-2\left(\theta_{t}-\theta_{0}\right)}{K-Z} \ln \left(\frac{2-e}{e}\right)\right]}
$$

where $b=0.005^{\circ} \mathrm{C}^{-1}$ is the linear trend of the damage; $d=0.03$ is the magnitude of the jump ; $e=0.1$ controls the steepness of the jump ; $K=1.3^{\circ} \mathrm{C}$ and $Z=2.7^{\circ} \mathrm{C}$ are the temperatures where the non-linear transition begins and ends. With such a function, damages remain small and practically linear until the temperature has increased by $K=1.3^{\circ} \mathrm{C}$ Celsius. Then, over the temperature interval $\left[1.3,2.7^{\circ} \mathrm{C}\right]$, damages rise steeply to about $d=3 \%$ points of the gross output. This alternative representation of damages avoids some of the noted drawbacks of the power function, like excessive damages for high temperature rise, while allowing non-negligeable damages for temperature increases in the range of 2.5 degrees Celsius [5].

\section{Treatment of Uncertainty}

Let us now discuss the issue of uncertainty on the climate. Climate uncertainty is captured by recognizing in the modelling design that today we ignore the true value of

\footnotetext{
${ }^{3}$ For alternative specifications of thresholds in climate change, see also [12].
} 
the 'climate sensitivity' parameter, i.e. the elevation in temperature for a doubling in GHGs atmospheric concentrations. While yet unknown, the IPCC [11] reports that the value of the climate sensitivity parameter can be included in a range of 1.4 and $4.5^{\circ} \mathrm{C}$.

Climate sensitivity is represented by a random variable and the model is designed to solve the maximization of the discounted expected utility of consumption (see Appendix A). Once information is obtained, variables in subsequent periods depend on the possible values of the observation.

We approximate uncertainty through a discrete probability implying three states of nature each characterized by a value of the 'climate sensitivity' parameter. The three sample values are chosen in order to offer the best compromise between diversity and 'plausibility' as suggested by Ha-Duong [8]. The samples proposed result in a low $\left(\theta_{2 \times}=1.4^{\circ} \mathrm{C}\right)$, a high $\left(\theta_{2 \times}=4.0^{\circ} \mathrm{C}\right)$ and a central $\left(\theta_{2 \times}=2.9 \mathrm{deg} \mathrm{C}\right)$ climate sensitivity. The central value $(2.9 \mathrm{deg} \mathrm{C})$ happens to be the parameter value retained in the original DICE 99 model. We have assumed equal probabilities of $33 \%$ for these three samples ${ }^{4}$.

\section{$3 \quad$ Results and policy lessons}

First we present the effect on abatement efforts of including CCS in a cost-efficiency analysis with a concentration target of 550 ppmv. [1, 23] used this same target for their analysis of the optimal mitigation portfolio. In a cost-efficiency setting, CCS is an option to reduce emissions and reach the target while avoiding some abatement

\footnotetext{
${ }^{4} \mathrm{~A}$ uniform probability distribution for these three values of the climate sensitivity belongs to the set of credible probability distributions determined by Ha-Duong [8] using the data on expert's opinion collected by Morgan and Keith [16].
} 
efforts. While previous papers that presented cost-efficiency models showed that, in the long-term, CCS could have a significant place into the portfolio of emissions reduction measures, they did not explicitly calculate the amount of early abatement efforts that could be avoided.

Second, we present the effect of including CCS within a cost-benefit analysis. In this framework, CCS can still be used to avoid some abatement efforts but it can also be a tool to further lower the optimal emission trajectory. Which effect is going to dominate has to do with how marginal damages depend on emissions. In order to improve insights and gain in results robustness we looked at the effect of CCS with two different versions of the DICE model: one with the usual quadratic damage function, and the other with a threshold damage function, both described in the preceding section.

\subsection{Cost-efficient policy, the 550 ppmv target}

Let us begin by describing the optimal policy that allows to stabilize carbon atmospheric concentration at 550 ppmv. No climate damages enter the objective function and, since the target refers to carbon concentration, uncertainty on the evolution of the temperature does not matter.

Even when the CCS option is not available, the levels of abatement required are quite low. This mainly derives from the fact that baseline emissions grow moderately and reach $15 \mathrm{GtC}$ in 2100 , which is a relatively low level ${ }^{5}$. Marginal abatement costs are also quite low, and until 2040 remain under $10 \mathrm{USD} / \mathrm{tC}$, which is the threshold for

\footnotetext{
${ }^{5}$ For instance when compared with the B2 marker scenario of IPCC SRES [3, 17], where emissions grow over $23 \mathrm{GtC}$ in 2100.
} 
CCS to become competitive. As a consequence, cumulated sequestration by 2100 is modest (55 GtC).

Still, CCS availability from 2030 allows to bypass a significant share of the modest reduction efforts engaged in 2000-2029 (see Table 1 for a summary of the main results). More than $20 \%$ of those otherwise optimal abatement efforts are now bypassed. Reduction of emissions is postponed to later periods where CCS is available. When CCS is an option for the later future, abatement costs are in 2010 roughly $40 \%$ lower than what they would be otherwise. Costs avoided are comparatively higher than avoided efforts because the cost function is a power function in abatement effort.

Table 1: Effect of CCS availability on cost-efficient abatement. Target: 550 ppm.

\begin{tabular}{lccc}
\hline \multicolumn{2}{l}{ Cost-efficiency analysis (DICE model with climate target, no damages) } \\
& 2010 & 2020 & 2050 \\
\hline Reduction from baseline, except CCS (MtC) & & & \\
CCS available from 2030 & 130 & 221 & 873 \\
CCS unavailable & 169 & 287 & 1,132 \\
$\Delta \%$ reduction (CCS vs. no CCS) & $-23 \%$ & $-23 \%$ & $-23 \%$ \\
Avoided abatement cost & $-44 \%$ & $-44 \%$ & $-43 \%$ \\
$\Delta \%$ costs (CCS vs. no CCS) & 0 & 0 & 88 \\
$C C S(M t C)$
\end{tabular}

The 550 ppmv target is central in the debate of mitigation policies. However, the concern of those who object to a 550 ppmv stabilization target is that it may imply an increase in temperature that might be dangerous. Indeed, within the DICE model, the cost-efficient 550 ppmv concentration target implies a temperature rise slightly above 2 degrees Celsius by 2100 and a continued increase during the next century. CCS could also offer an opportunity to tighten the policy target rather than to postpone efforts. 
For this reason, in the next subsection a cost-benefit analysis framework is adopted to explore this question.

\subsection{Optimal policy, cost-benefit analysis}

The following results (see Table 2) are obtained by applying a cost-benefit analysis, first considering deterministic assumptions on the climate sensitivity parameter. The parameter is assumed to take its central value of $2.9^{\circ} \mathrm{C}$, as in the original DICE model. Results obtained with both damages functions are presented.

Table 2: Effect of CCS availability on non-CCS optimal abatement.

Cost-benefit analysis - DICE model, quadratic and threshold damage functions

\begin{tabular}{lccc}
\hline \hline Emission reductions from baseline & 2010 & 2020 & 2050 \\
\hline Quadratic damage function & & & \\
Emission reduction, except CCS (MtC) & & & \\
CCS available from 2030 & 603 & 849 & 1,864 \\
CCS unavailable & 606 & 853 & 1,872 \\
$\Delta \%$ reduction (CCS vs. no CCS) & $-5 \%$ & $-5 \%$ & $-5 \%$ \\
Total reduction, including CCS (MtC) & & & \\
CCS available from 2030 & & & 2,434 \\
$\Delta$ Total reduction (CCS vs. no CCS) & & & $+30 \%$ \\
\hline Threshold damage function & & \\
Emission reduction, except CCS (MtC) & 585 & 828 & 2,130 \\
CCS available from 2030 & 649 & 936 & $-17 \%$ \\
CCS unavailable & $-10 \%$ & $-12 \%$ & \\
$\Delta$ \% reduction (CCS vs. no CCS) & & 2,837 \\
Total reduction, including CCS (MtC) & & & $+10 \%$ \\
CCS available from 2030 & & \\
$\Delta$ Total reduction (CCS vs. no CCS) & & \\
\hline \hline
\end{tabular}

In contrast to cost-efficiency analysis, CCS availability by 2030 brings modest relative changes to near-term optimal emissions reductions from baseline, even though the optimal reductions are larger than in the cost-efficiency scenario. The effect of CCS 
availability is twice larger $(-10 \%)$ when considering the threshold damage function than when the quadratic damage function is used (-5\%). Indeed, with the threshold damage function, the shadow price of emissions becomes more dependent on the level of emissions whereas with the quadratic damage function, the DICE model is known to exhibit a shadow price that is relatively independent of the emissions level (see [22]).

After 2030, the effect of CCS on abatement remains unchanged with the quadratic damage function, while it increases when damages are represented by a threshold function. However, the use of CCS does more than compensate for these avoided abatement efforts and the total reduction in emissions is larger. Clearly, CCS appears to be an option to engage in a more stringent control of climate change and not only an option to substitute some part of costly abatement efforts. As a consequence, optimal CO2 concentration and temperature levels reached by 2100 are lower when CCS is available (see Table 3). The impact of CCS is less visible in the case a threshold damage function is considered, given that the balancing of cost and benefits already leads to a more stringent reduction in emissions.

Table 3: Summary of environmental variables in 2100. Optimal policy (cost-benefit analysis). DICE model, quadratic or threshold damage function.

\begin{tabular}{lcccc}
\hline \hline Damage function & $\begin{array}{l}\text { Quad. } \\
\text { Concentration (ppm) }\end{array}$ & $\begin{array}{c}\text { Thresh. } \\
\text { Warming }\end{array}$ & $\begin{array}{l}\text { Thresh. } \\
\text { (Celsius) }\end{array}$ \\
\hline CCS & 537 & 503 & 2.03 & 1.95 \\
No CCS & 552 & 509 & 2.08 & 1.97 \\
\hline \hline
\end{tabular}




\subsection{Optimal hedging policy}

Let us now discuss how uncertainty on climate sensitivity may modify the policy lessons obtained in the previous section.

Uncertainty about climate sensitivity is assumed to be resolved by 2040. After that date, policy decisions depend on the information obtained. Before that date, policy decisions are the same for all states of nature. What is effect of CCS when climate uncertainty is included in the analysis? Does it play a more important role when designing an optimal hedging strategy?

The conclusion happens to be qualitatively dependent on the shape of the damage function. With the standard damage function, uncertainty narrows the difference between the two near-term hedging strategies, with and without CCS available, respectively. Indeed, the future availability of CCS allows to reduce the volume of abatement efforts by only $0.5-0.7 \%$ from 2010 to 2030 (while it accounted for a $5 \%$ reduction in the case without uncertainty). Conversely, with a threshold damage function, uncertainty widens the difference between the two hedging strategies, again with and without future availability of CCS. Indeed, the future availability of CCS allows to reduce the volume of abatement efforts by $12-16 \%$ (it was $10-14 \%$ without uncertainty).

In addition, the limited difference in near-term policies between scenarios with or without CCS suggests that the value of information regarding potential costs of carbon sequestration would be relatively small ${ }^{6}$ in particular when compared to the value of

\footnotetext{
${ }^{6}$ This result may partially derive from model limitations in the description of the energy system. Indeed, anticipating the availability of CCS technologies may affect the choice among alternative structural evolutions of the energy system [6] which would imply higher value of information concerning CCS.
} 
Table 4: Effect of CCS availability on non-CCS optimal abatement and costs.

Effect on the optimal hedging policy

DICE model, quadratic and threshold damage functions

\begin{tabular}{lcc}
\hline \hline & 2010 & 2020 \\
Quadratic damage function & & \\
Effect of uncertainty on avoided reduction & - & - \\
Effect of uncertainty on avoided abatement costs & - & - \\
Threshold damage function & & \\
Effect of uncertainty on avoided reduction & + & + \\
Effect of uncertainty on avoided abatement costs & ++ & ++ \\
\hline \hline
\end{tabular}

getting better information on the climate cycle uncertainty.

\section{Conclusions}

As recalled by Holloway [10], the geological storage of CO2 needs to be guaranteed at least 'until there has been a significant decline in the atmospheric CO2 levels'. Thus the necessary time frame for storage might be in the range of a few hundred years to a few thousand years. In any case, this is 'greater than the likely lifetime of any corporation' and raises the issue of liability and of acceptability of this option by the public.

Nevertheless, Carbon Capture and Sequestration technologies are recognized as a promising and, in many ways, politically attractive way of reducing emissions without dramatically changing the fuel mix or the energy intensity of the economy. Indeed, CCS singles out from other mitigation actions, such as the reduction of energy demand and the switching towards carbon-free energy, which would imply more profound changes to the economy energy future (see for instance[7]). For these reasons, the debate concerning CCS has grown and the discussion has often focused on the potential cost 
reduction that could be obtained through learning-by-doing and R\&D expenditures and the resulting rates of penetration of sequestration technologies.

In this paper we have taken a slightly different perspective, asking the question of what should the optimal emission strategy be, admitting that the CCS option may become available at reasonable costs in the future. The main result of the analysis can be synthesized in the idea that if CCS is considered as an option, then more ambitious (stringent) environmental targets should be aimed for. Under standard assumptions about damages and climate sensitivity uncertainty, cost-benefit analysis suggests that the future availability of CCS is not a reason to bypass near-term abatement. In conclusion, until better information concerning these uncertainty sources is obtained, CCS reductions should be considered as mostly additional to traditional abatement effort. 


\section{A Summary of the model}

The model solves the following problem.

$$
\max _{v_{0}, \ldots, v_{T_{L}-1}} \mathbb{E}\left\{\sum_{t=0}^{T_{L}-1} U_{t}\left(c_{t}\right)+\mathbb{E}\left[\max _{\left(v_{T_{L}}\left(\theta_{2 \times}\right), \ldots, v_{T}\left(\theta_{2 \times}\right)\right)} \sum_{t=T_{L}}^{T} U_{t}\left(c_{t}\left(\theta_{2 \times}\right)\right) \mid \theta_{2 \times}\right]\right\}
$$

Decision variables $v_{t}=\left(\mu_{t}, \mu_{t}^{c c s}, b_{t}\right)$ where $\mu_{t}$ is the rate of abatement, $\mu_{t}^{c c s}$ is the rate of emissions captured and sequestrated, $b_{t}$ is the rate of investment.

Uncertainty: climate sensitivity, $\theta_{2 \times}(\omega) \in\left\{1.2,2.9,4.0^{\circ} \mathrm{C}\right\}$

Laws of motion: (1) Capital accumulation $K_{t}$; (2) Atmospheric concentration of carbon dioxide $M_{t}$; (3) Other Environmental Variables $X_{t}$ (including $\theta_{t}$, the increase in atmospheric temperature):

$$
\begin{aligned}
& K_{t+1}=(1-\delta) K_{t}+10 b_{t} \mathcal{Y}_{t}\left(\mu_{t}, \mu_{t}^{c c s}, X_{t}, K_{t}\right) \\
& M_{t+1}=\alpha_{M} M_{t}+h\left(X_{t}\right)+\beta \mathcal{E}_{t}\left(K_{t}, \mu_{t}, \mu_{t}^{c c s}\right)+L U_{t} \\
& X_{t+1}=g\left(X_{t}, M_{t}, \omega\right)
\end{aligned}
$$

Intermediate Variables $Y_{t}=$ Available output; $c_{t}=$ total consumption; $E_{t}=$ Emissions; $D_{t}\left(X_{t}\right)=$ Climate damages; $C_{t}\left(\mu_{t}\right)=$ cost of abatement; $C_{t}^{c c s}\left(\mu_{t}^{c c s}\right)=$ cost 
of capture and sequestration.

$$
\begin{aligned}
& Y_{t}=\left[1-D_{t}\left(X_{t}\right)\right]\left[1-C_{t}\left(\mu_{t}\right)-C_{t}^{c c s}\left(\mu_{t}^{c c s}\right)\right] F_{t}\left(K_{t}\right) \\
& c_{t}=\left(1-b_{t}\right) Y_{t} \\
& E_{t}=\left[1-\mu_{t}-\mu_{t}^{c c s}\right] \sigma_{t}^{0} F\left(K_{t}\right) \\
& \text { For } t<T_{L} \quad D_{t}\left(X_{t}\right)=0 \quad \text { for } t \geq T_{L} \quad D_{t}\left(X_{t}\right)=D\left(\theta_{t}\right) \quad \text { (see section 2) }
\end{aligned}
$$

The time horizon is $T=40$. Time step $t=0$ corresponds to the period 2000-2009. The date of arrival of information, $T_{L}$, to the period 2030-2040.

Initial conditions are $K_{0}, M_{0}, X_{0}$. The cost functions $C_{t}(\cdot)$ and $C_{t}^{c c s}(\cdot)$ are strictly increasing and convex. Utility is defined by $U_{t}=\frac{1}{(1+\delta)^{t}} \log \left(c_{t}\right)$. The production function $F_{t}$ is concave and defined through exogenous time dependent parameters (labor input and total factor productivity).

\section{References}

[1] K. Akimoto, T. Tomoda, Y. Fujii, and K. Yamaji. Assessment of global warming mitigation options with integrated assessment model DNE21. Energy Economics, $26: 635-653,2004$.

[2] P. Ambrosi, J.-C. Hourcade, S. Hallegatte, F. Lecocq, P. Dumas, and M. HaDuong. Optimal control models and elicitation of attitudes towards climate change. Environmental Modeling and Assessment, 8(3):135-147, 2003. Special Issue on 
Modeling the economic response to global climate change.

[3] I. D. D. Centre. The SRES98 emissions scenarios. Technical report, University of East Anglia, 1999.

[4] K. Damen, A. Faaij, F. van Bergen, and J. G. ad Erik Lysen. Identification of early opportunities for CO2 sequestration — worldwide screening for CO2-EOR and CO2-ECBM projects. Energy, 30:1931-1952, July 2005.

[5] P. Dumas and M. Ha-Duong. An abrupt stochastic damage function to analyse climate policy benefits. In A. Haurie and L. Viguier, editors, The coupling of climate and economic dynamics, Essays on Integrated Assessment. Springer, 2005.

[6] A. Gritsevskyi and N. Nakićenović. Modeling uncertainty of induced technological change. Energy Policy, 28:907-921, 2000.

[7] M. J. Grubb. Technologies, energy systems and the timing of $\mathrm{CO}_{2}$ emissions abatement. Energy Policy, 25(2):159-172, 1997.

[8] M. Ha-Duong. Imprecise probability bridge scenario-forecast gap. In Annual Meeting of the International Energy Workshop, Laxenburg, Austria, 24-26 June 2003. Jointly organized by EMF/IEA/IIASA.

[9] M. Ha-Duong and D. Keith. Carbon storage: the economic efficiency of storing $\mathrm{CO}_{2}$ in leaky reservoirs. Clean Technology and Environmental Policy, 5(2/3), Oct. 2003. Special issue on Technologies for Sustainable Development. 
[10] S. Holloway. Underground sequestration of carbon dioxide - a viable greenhouse gas mitigation option. Energy, 30:2318-2333, 2005.

[11] IPCC. Climate Change 2001: the scientific basis. Cambridge University Press, 2001. Contribution of the Working Group I to the Third Assessment Report of the Intergovernmental Panel on Climate Change.

[12] K. Keller, B. M. Bolker, and D. F. Bradford. Uncertain climate tresholds and economic optimal growth. Journal of Environmental Economics and Management, 48(1):723-741, July 2004.

[13] K. Keller, Z. Yang, M. Hall, and D. F. Bradford. Carbon dioxide sequestration: when and how much? Center for Economic Policy Studies Working Paper 49, Princeton University, Sept. 2003.

[14] C. D. Kolstad. George Bush versus Al Gore. Irreversibilities in the greenhouse gas accumulation and emission control invesment. Energy Policy, 22(9):771-778, 1994.

[15] F. Lecocq and K. Chomitz. Optimal use of carbon sequestration in a global climate change strategy. Technical Report 2635, World Bank, July 2001.

[16] M. G. Morgan and D. Keith. Subjective judgments by climate experts. Environmental Science and Technology, 29(10):468A-476A, Oct. 1995.

[17] N. Nakićenović, editor. Special Report on Emissions Scenarios. Cambridge University Press, 2000.

[18] W. D. Nordhaus. Managing the Global Commons. MIT Press, 1994. 
[19] W. D. Nordhaus and J. Boyer. Warming the World: Economics Models of Global Warming. MIT press, 2000.

[20] W. D. Nordhaus and D. Popp. What is the value of scientific knowledge? Energy Journal, pages 1-23, 1997. Previously Yale University, Cowles Foundation Discussion Paper 1117, March 1996.

[21] S. C. Peck and T. J. Teisberg. Global warming uncertainties and the value of information: An analysis using CETA. Resource and Energy Economics, 15:7197, 1993.

[22] W. A. Pizer. Combining price and quantity controls to mitigate global climate change. Journal of Public Economics, 85:409-434, 2002.

[23] K. Riahi, E. S. Rubin, M. R. Taylor, L. Schratenholzer, and D. Hounshell. Technological learning for carbon capture and sequestration technologies. Energy Economics, 26(4):539-564, 2004. 